\title{
BMJ Open Does deprivation affect the demand for NHS Direct? Observational study of routine data from Wales
}

\author{
Julie Peconi (D) , ${ }^{1}$ Steven Macey, ${ }^{2}$ Sarah E Rodgers (D) , ${ }^{1,3}$ Ian T Russell, ${ }^{1}$ \\ Helen Snooks, ${ }^{1}$ Alan Watkins (i) ${ }^{1}$
}

To cite: Peconi J, Macey S, Rodgers SE, et al. Does deprivation affect the demand for NHS Direct? Observational study of routine data from Wales. BMJ Open 2019;9:e029203. doi:10.1136/ bmjopen-2019-029203

- Prepublication history for this paper is available online. To view these files, please visit the journal online (http://dx.doi. org/10.1136/bmjopen-2019029203).

Received 16 January 2019 Revised 02 September 2019 Accepted 09 September 2019

Check for updates

(c) Author(s) (or their employer(s)) 2019. Re-use permitted under CC BY-NC. No commercial re-use. See rights and permissions. Published by BMJ.

${ }^{1}$ Medical School, Swansea University, Swansea, UK

${ }^{2}$ Welsh Government, Swansea, UK

${ }^{3}$ Department of Public Health and Policy, University of Liverpool, Liverpool, UK

Correspondence to

Dr Julie Peconi;

j.peconi@swansea.ac.uk

\section{ABSTRACT}

Objective To estimate the effect of deprivation on the demand for calls to National Health Service Direct Wales (NHSDW) controlling for confounding factors.

Design Study of routine data on over 400000 calls to NHSDW using multiple regression to analyse the logarithms of ward-specific call rates across Wales by characteristics of call, patient and ward, notably the Welsh Index of Multiple Deprivation.

Setting 810 electoral wards with average population of 3300, defined by 1998 administrative boundaries.

Population All calls to NHSDW between January 2002 and June 2004.

Main outcome measures We used ward populations as denominators to calculate the rates of three categories of calls: calls seeking advice, calls seeking information and all calls combined.

Results Confounding variables explained $31 \%$ of variation in advice call rates, but only $14 \%$ of variation in information call rates and in all call rates (all significant at $0.1 \%$ level). However, deprivation was only a statistically significant predictor of information call rates. The proportion of the ward population categorised as 'white' was a highly significant predictor of all three call rates. For advice calls and combined calls, rates decreased highly significantly with the proportion of those who called the service for themselves. Information call rates were higher on weekdays and highest on Mondays, while advice call rates were highest on Sundays.

Conclusions Deprivation had no consistent effect on demand for the service and the relationship needs further exploration. While our data may have underestimated the 'need' of deprived patients, they yield no evidence that policy-makers should seek to improve demand from those patients. However, we found differences in the way callers use advice and information calls. Previously unexplored variables that help to predict ward-specific call rates include: ethnicity, day of the week and whether patients made the calls themselves.

\section{INTRODUCTION}

Healthcare is free of charge in the UK and equal access for all is one of the guiding principles of the National Health Service (NHS). The founders of the NHS believed that inequalities in access would fade away. Yet those most disadvantaged often make less

\section{Strengths and limitations of this study}

- This is the first large, national study in Wales to explore the demand for telephone-based healthcarewith data on over 400000 calls over 30 months.

- This is the first study to make a distinction between calls for advice (eg, immediate help for illness) and calls for information only (eg, how to quit smoking).

- Fully to understand the influence of deprivation on demand we included 14 potential independent variables, many of which (eg, who made the call, distance to nearest emergency department and population density), were previously unexplored.

- Limitations include that, as we could not trace callers through the dataset, we were unable to distinguish between many unique calls or the same caller phoning several times.

- Our study is also limited by the 'ecological fallacy'-the danger of inferring individual trends from grouped data.

use of services ${ }^{1}$ and those living in deprived areas generally have worse health status. ${ }^{2-4}$ So improving access to health services for those who are disadvantaged is a prerequisite for improving the health of the population. The provision of healthcare over the telephone eliminates issues of location-of patient and provider-potentially enabling policy-makers to improve access. NHS England introduced NHS Direct (NHSD), a 24-hour nurse-led health information telephone line, to provide 'easier and faster advice and information to people about health, illness and the NHS, so that they can better care for themselves and their families'. More recently ' 111 ' has replaced NHSD as the number to ring in England to facilitate access to the many urgent care services. ${ }^{6}$ The 111 services now exist both in Scotland (NHS 24) and alongside NHS Direct in Wales (NHS Direct Wales $($ NHSDW)). Callers can use these services to seek advice (eg, on which further healthcare service to use) or for information only (eg, location of nearest pharmacy). Indeed 
in Wales, 111 is described as 'a national single point of access to a wide range of reliable information, advice and assistance' ${ }^{7}$

With the introduction of 111 the telephone continues to play an important role in healthcare access. However, early concerns from evaluators, ${ }^{8}$ policy-makers ${ }^{9}$ and nurses ${ }^{10}$ suggested that NHSD and its counterparts were not reaching all the population equally. Indeed early evidence suggested that NHSD was generally used by those who are less disadvantaged: individual socioeconomic indicators showed patients were less likely to use the service if: they did not own a car or lived in rented or social housing ${ }^{11-13}$; had left education at a young age or with fewer qualifications ${ }^{12}$ or had lower household incomes or manual jobs. ${ }^{13}$ Evidence at area level about calls to NHSD in England is also mixed. Across all calls there appears to be a general increase in call rates with deprivation ${ }^{14}$ although this drops off in the most deprived areas. ${ }^{1516}$ However, call rates for children were lower in the most deprived areas ${ }^{141617}$; while call rates for males and older people were higher in the most deprived areas. ${ }^{14} 17$ Other studies showed no clear relationship between deprivation and use. ${ }^{18}{ }^{19}$ In contrast deprivation increased the chance that those calling NHSD in Wales would receive more urgent advice, especially to call an emergency ambulance. ${ }^{20}$

This evidence shows that the use of healthcare is complex; to understand access correctly, one must take account of all contributing factors. ${ }^{21}$ Confounding variables are those whose relationship with both dependent and independent variables can obscure true associations. ${ }^{22}{ }^{23}$ For example, the relationship between call rates and deprivation changes when age and gender are considered. This is also apparent in studies exploring access to telephone advice across general practitioner out-of-hours (GP OOH) services, which suggest an interaction between use and distance $\mathrm{e}^{24-26}$ and between use and the rurality of an area. ${ }^{25}$ However, the existing literature on NHSD often relates demand to patient deprivation in isolation and rarely considers other confounding variables. Furthermore, all researchers have combined calls for advice with those only for information before analysis. However, there is no evidence that these types of calls are homogeneous. By analysing over 400000 anonymous calls to NHS Direct in Wales, we aimed to estimate the intrinsic effects of deprivation on the demand for advice calls and information calls separately, after controlling for potential confounding factors. Though these calls are 15 years old, we know of no new policy initiatives in Wales targeting access to healthcare specifically by socioeconomic groups. Furthermore, most of the existing literature is no younger and less rigorously analysed.

\section{METHODS}

This doctoral study analysed routinely collected data on calls to NHSDW. We complemented these with data on the associated wards, notably from the 2001 Census. We describe our methods in full elsewhere. ${ }^{27}$

\section{Patient and public involvement}

As doctoral researcher and supporting committee, we analysed anonymous routine data acquired from the NHSDW. We judged that it would have been difficult to engage relevant patients or members of the public in this mainly technical task.

\section{Time and place}

In 2003, Wales comprised 22 unitary authorities or 865 electoral wards with an average population of 3300 . We acquired anonymous data on all calls to NHSDW originating from Wales between January 2002 and June $2004(\mathrm{n}=615739)$. To protect patient confidentiality, an NHSDW data analyst removed all patients' identifying information, replacing this information with unitary authority, ward and the Welsh Index of Multiple Deprivation (WIMD) as an indicator of deprivation. Though this was necessary for ethical approval, we lost the ability to link calls and identify repeat callers. We excluded duplicate records of known calls, and calls which had been transferred from an emergency department (ED) or GP OOH services. We also excluded 59253 patients without information on postcode since we could not assign a WIMD score or other ward-specific data. Initial exploration of the data suggested that NHSD in England had received the majority of calls from Flintshire and one adjacent ward in Wrexham. NHSD confirmed that these wards had English dialling codes, which routed calls automatically to England. We, therefore, excluded all calls from these areas. ${ }^{27}$ The final number of calls available for analysis was 409611 across 810 wards (figure 1).

We separated calls seeking advice on symptoms from those seeking only information. As potential explanatory variables we included several reported in the literature as affecting demand and others new in our dataset and thus previously unexplored (table 1 ). We considered two categories of such variables-relating to the call or to the ward.

\section{Data}

\section{Individual NHSDW call variables}

For all calls NHSDW provided data on date and type (advice or information), age, gender, ethnicity and presenting symptom of the patient, the relationship of caller to patient and the advice given by the NHSDW nurse advisor.

We analysed the effect of deprivation and other variables on call rates by ward, the natural unit of analysis. So we converted individual variables to proportions by ward, for example, the proportion of females per ward. Before doing so, we coded symptoms according to the International Classification of Primary Care-2 (ICPC$2)^{28}$; ethnicity data according to the Office for National Statistics (ONS) categories ${ }^{29}$ and relationship of caller to patient as self or surrogate. From the date of the call, 


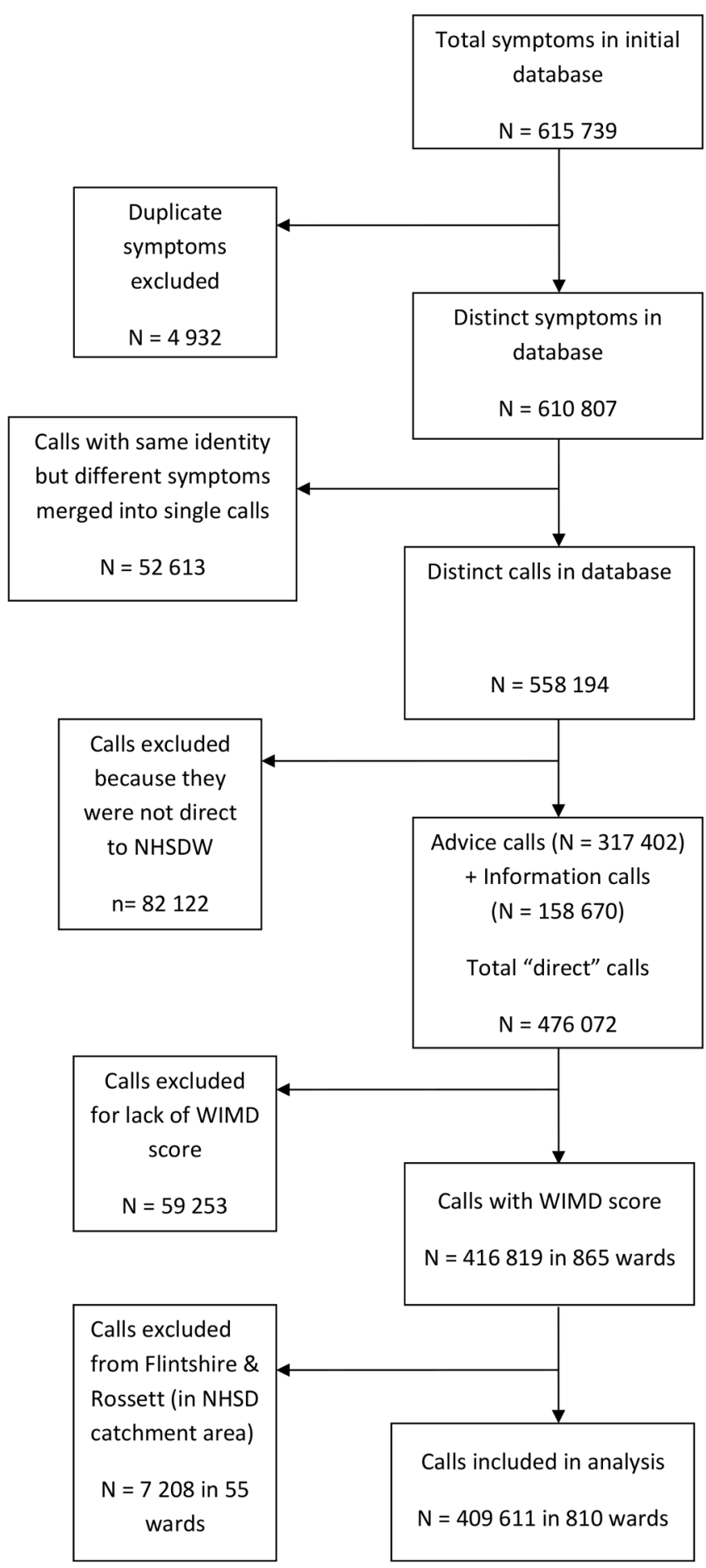

Figure 1 Flow chart showing selection of calls for analysis. NHSD, National Health Service Direct; NHSDW, National Health Service Direct Wales; WIMD, Welsh Index of Multiple Deprivation.

we calculated the day of the week. As some patients call NHSDW frequently, it would have been much less robust to analyse the characteristics of individual callers.

\section{Ward-specific variables}

Our main explanatory variable was the WIMD, the deprivation index used in Wales during data collection and since. Although used mainly as a single score, the WIMD comprises six domains of deprivation: (1) income (with a weight of $25 \%),(2)$ employment $(25 \%)$, (3) health and disability $(15 \%)$, (4) education, skills and training $(15 \%)$, (5) housing $(10 \%)$ and (6) geographical $(10 \%) .{ }^{30}$ The least deprived ward in Wales at the time of data collection was Cyncoed in Cardiff, a ward including a small village with some of the highest property prices and the most popular schools and a WIMD score of 1.13. The most deprived ward was Rhyl West, a seaside town with many inhabitants receiving governmental financial assistance, with a WIMD score of 74.9. Figure 2 shows variation in WIMD scores across Wales. To each call with a defined postcode (each of which covered an average of 18 residents), the NHSDW data analyst assigned the WIMD score for the corresponding ward.

We mapped the location of each of the 23 hospitals in Wales or on the English-Welsh border with an ED at the time of data collection. As data on individual distances to ED were not available, we used the geographical centroid of each ward (the geometric centre of the ward's shape) to calculate the straight-line distance for patients in that ward to the nearest ED. This is a widely accepted measure for estimating distances to health services. ${ }^{31}{ }^{32}$ As an indicator of the concentration of people in a ward, we derived population density from the 2001 Census and the 2003 ward boundaries using GeoConvert. ${ }^{33}$ Though NHSDW had provided the age, gender and ethnicity of individual patients, we derived the corresponding ward-specific proportions from the more accurate 2001 Census (table 1).

\section{Outcome measures and statistical methods}

As calls for advice differ in purpose and practice from calls only for information, we used three dependent variables for wards-call rates for advice, calls for information and total calls. We calculated these by dividing the number of each type of call in each ward by the 2001 Census population of that ward from the ONS. As early analysis showed that the distribution of residuals was not normal, we transformed call rates by taking square roots and logarithms. As the logarithmic transformation brought the distribution of residuals much closer to normality, we adopted that throughout. We used SPSS V.16.0 to develop multiple linear regression models for each of our three outcome measures. First we entered all variables except day of the week and deprivation; then we added weekday; and finally we added 'deprivation' as a continuous variable. By adding deprivation to the statistical model at the final step we were able to estimate its true contribution after accounting for known and potential confounding variables. We assessed multicollinearity using tolerance levels provided by the regression package. ${ }^{27}$

Most NHSDW variables were missing fewer than $1 \%$ of their data. Not surprisingly very few $(3.1 \%)$ of those calling only for information had a symptom recorded. Hence, when we analysed information call rates, we did not include symptom as a potential confounding variable. Though NHSDW collected ethnicity data only in the final 
Table 1 Study variables

\begin{tabular}{|c|c|c|c|}
\hline Variable & Definition of categories & Equivalent ward variable & $\begin{array}{l}\text { Confounder from literature } \\
\text { on NHS Direct }\end{array}$ \\
\hline \multicolumn{4}{|l|}{ NHSDW call variables } \\
\hline Type of call & For advice; only for information & $\begin{array}{l}\text { Proportion of advice calls from } \\
\text { ward }\end{array}$ & No \\
\hline Patient's age & Age in completed years & $\begin{array}{l}\text { Mean age of ward population from } \\
2001 \text { Census }\end{array}$ & Yes (refs ${ }^{141617}$ ) \\
\hline Patient's main symptom & $\begin{array}{l}\text { International Classification of } \\
\text { Primary Care } 2^{28}\end{array}$ & $\begin{array}{l}\text { Proportion of patients with } \\
\text { digestive symptoms (most } \\
\text { common) in ward }\end{array}$ & No \\
\hline Patient's ethnicity & $\begin{array}{l}\text { White, other specified ethnicity, not } \\
\text { specified }\end{array}$ & $\begin{array}{l}\text { Proportion of 'white' residents in } \\
\text { ward from } 2001 \text { Census }\end{array}$ & Not together with deprivation \\
\hline Advice given & Advice given by NHSDW & $\begin{array}{l}\text { Not applicable (analysed in } \\
\text { reference 20) }\end{array}$ & No \\
\hline \multicolumn{4}{|l|}{ Ward variables } \\
\hline $\begin{array}{l}\text { Call rate } \\
\text { (dependent variable) }\end{array}$ & Not applicable & $\begin{array}{l}\text { No of calls from ward divided by } \\
2001 \text { Census population }\end{array}$ & Not applicable \\
\hline $\begin{array}{l}\text { Deprivation score (main } \\
\text { explanatory variable) }\end{array}$ & Not applicable & $\begin{array}{l}\text { Measured by Welsh Index of } \\
\text { Multiple Deprivation }{ }^{26}\end{array}$ & Yes (refs ${ }^{14161819}$ ) \\
\hline Distance to ED & Not applicable & $\begin{array}{l}\text { Measured by straight line from } \\
\text { geographical centroid of ward to } \\
\text { nearest ED }\end{array}$ & No \\
\hline
\end{tabular}

ED, emergency department; NHS, National Health Service; NHSDW, National Health Service Direct Wales.
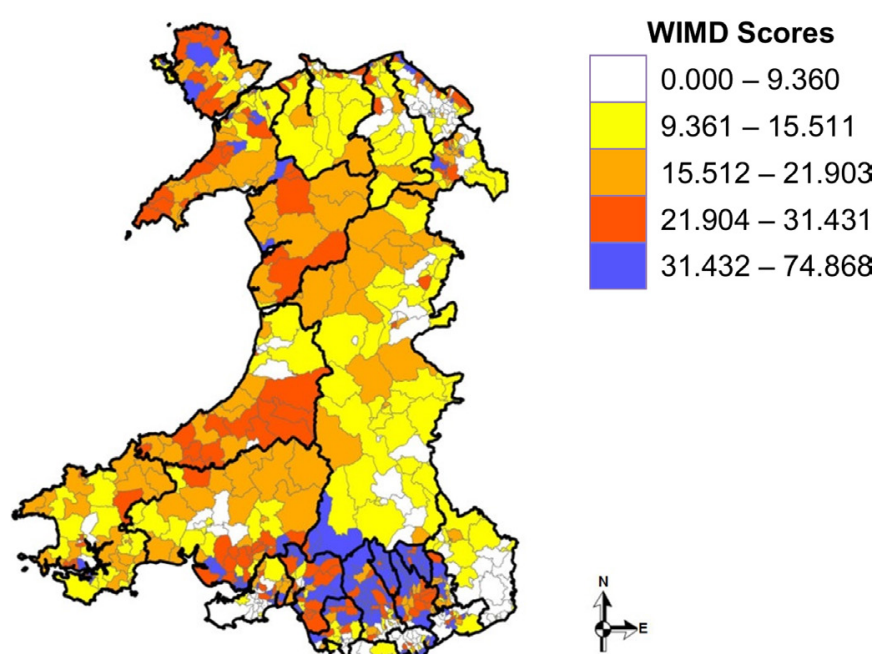

Figure 2 Variation in WIMD scores across Wales. 'Welsh boundaries were derived from Edina Digimap (https:// digimap.edina.ac.uk), an online map and data delivery service run by University of Edinburgh. WIMD scores were transposed onto the Welsh map using ArcGIS (www.arcgis. com), a geographical information system for maps and spatial data'. WIMD, Welsh Index of Multiple Deprivation. year, we were able to derive appropriate proportions by ward (table 2). As we could not identify repeat callers, we could not estimate the effect of different advice given on future calls, and therefore did not include advice as a potential confounding variable. Instead we report elsewhere on the effect of deprivation on the advice given by the NHSDW. ${ }^{20}$

\section{RESULTS}

Table 2 summarises the patients and their calls to NHSDW. Most calls (69\%) were for advice; more than half $(58 \%)$ were on the caller's behalf. Most patients (62\%) were female; the mean age of callers was 33.4 years-well below 40 , the average age of residents in Wales. ${ }^{27}$ Sunday was the most popular day for calls (16\%). More symptomatic calls concerned digestive symptoms (16\%) than any other group. Table 2 also suggests that call rates may have been highest among the most and least deprived groups. Table 3 aggregates data across wards. Call rates varied widely across the country with little discernible pattern (figure 3). Bronington in Wrexham, a rural ward close to the Welsh-English border had the lowest call rate at 0.029 
Table 2 Characteristics of patients and their calls $(n=409611)$

\begin{tabular}{lll}
\hline NHSDW call variable & $\begin{array}{l}\text { N of calls } \\
\text { made by each } \\
\text { subgroup }\end{array}$ & $\begin{array}{l}\text { \% of calls } \\
\text { made by each } \\
\text { subgroup }\end{array}$ \\
\hline Call type & 281223 & 68.7 \\
\hline $\begin{array}{l}\text { For advice } \\
\text { For information only }\end{array}$ & 128388 & 31.3 \\
\hline $\begin{array}{l}\text { Day on which call } \\
\text { occurred }\end{array}$ & & \\
\hline Sunday & 66297 & 16.2 \\
\hline Monday & 61502 & 15.0 \\
\hline Tuesday & 56341 & 13.8 \\
Wednesday & 55863 & 13.6 \\
\hline Thursday & 55488 & 13.5 \\
\hline Friday & 52836 & 12.9 \\
\hline Saturday & 61284 & 15.0 \\
\hline
\end{tabular}

\section{Relationship of caller to} patient

\begin{tabular}{|lcc|}
\hline Self & 237356 & 58.0 \\
\hline Surrogate & 172064 & 42.0 \\
\hline Not recorded & 191 & $<0.1$ \\
\hline Gender & & \\
\hline Male & 155279 & 38.0 \\
\hline Female & 253843 & 62.0 \\
\hline Not recorded & 489 & 0.12 \\
\hline Ethnicity & & \\
\hline $\begin{array}{l}\text { White background } \\
\text { Any other background }\end{array}$ & 390308 & 44.0 \\
\hline $\begin{array}{l}\text { Not recorded (mainly before } \\
\text { July 2003) }\end{array}$ & 225374 & 1.0 \\
\hline
\end{tabular}

\section{Symptom (from ICPC-2)}

\begin{tabular}{|lcc|}
\hline Digestive & 67190 & 16.4 \\
\hline General and unspecified & 32262 & 7.9 \\
\hline Skin & 30304 & 7.4 \\
\hline Musculoskeletal & 27982 & 6.8 \\
\hline Respiratory & 27325 & 6.7 \\
\hline Neurological & 21260 & 5.2 \\
\hline Female genital & 6929 & 1.7 \\
\hline Eye & 6390 & 1.6 \\
\hline Ear & 6410 & 1.6 \\
\hline Psychological & 6106 & 1.5 \\
\hline Urological & 5964 & 1.5 \\
\hline Pregnancy and childbearing & 4266 & 1.0 \\
\hline Cardiovascular & 2620 & 0.6 \\
\hline Male genital & 2387 & 0.6 \\
\hline Not recorded (mainly & 162216 & 39.6 \\
\hline information calls) & & \\
\hline
\end{tabular}

\section{Advice given}

999 or ambulance

12791

3.1
Table 2 Continued

\begin{tabular}{lcc}
\hline NHSDW call variable & $\begin{array}{l}\text { N of calls } \\
\text { made by each } \\
\text { subgroup }\end{array}$ & $\begin{array}{l}\text { \% of calls } \\
\text { made by each } \\
\text { subgroup }\end{array}$ \\
\hline ED or other hospital & 29865 & 7.3 \\
\hline Emergency GP or dentist & 89902 & 21.9 \\
\hline Other GP or dentist & 82149 & 20.1 \\
\hline Other & 27131 & 6.6 \\
\hline Self-care & 154584 & 37.7 \\
\hline Not assessed & 13189 & 3.2 \\
\hline Deprivation (from WIMD) & & \\
\hline Least deprived fifth & 83071 & 20.3 \\
\hline Second least deprived fifth & 64652 & 15.8 \\
\hline Third least deprived fifth & 74167 & 18.1 \\
\hline Fourth least deprived fifth & 85024 & 20.8 \\
\hline Most deprived & 102697 & 25.1 \\
\hline
\end{tabular}

ED, emergency department; GP, general practitioner; ICPC-2, International Classification of Primary Care-2; NHSDW, National Health Service Direct Wales; WIMD, Welsh Index of Multiple Deprivation.

per inhabitant over 30 months; Gorseinon East, a ward near Swansea, the second city of Wales, with a history of coal mining, tinplate factories and woollen mills, had the highest at 0.337 . Distances to hospital EDs ranged from 0.2 to $56 \mathrm{~km}$; and population density from 0.04 to 100 people per hectare. Ward populations were predominantly 'white' (98.6\%); $51.5 \%$ were female.

The correlation between advice call rates and information call rates was low $(r=0.097, p=0.006)$. Correlations between deprivation scores and call rates were positive for advice calls $(\mathrm{r}=0.166, \mathrm{p}<0.001)$ and negative for information calls $(\mathrm{r}=-0.123, \mathrm{p}<0.001)$. At first sight this suggests that the more deprived are more likely to phone NHSD for advice than for information. Table 4 shows variation in the correlations between deprivation scores and the proportion of calls by day of the week, suggesting that the more deprived are more likely to phone NHSD at weekends. These findings confirmed our plan to separate advice and information calls, then to model the effect of known confounding variables, next to add the effect of day of the week, and only finally to test whether deprivation improves the resulting models.

\section{Deprivation and demand for NHSDW}

We developed three multiple regression models to explore the relationship between deprivation and demand in the form of logarithms of call rates - for advice, for information and for advice or information (all calls combined). Tables 5-7 summarise the change in each model with the addition of each 'block' of explanatory variables. The known confounding variables ('Block 1') achieved the highest adjusted $R^{2}$ of 0.307 for advice call rates, compared with 0.141 for information call rates and 0.144 for all call rates (all significant at $0.1 \%$ level). In other 
Table 3 Characteristics of 810 wards: continuous (with means) and binary (with proportions)

\begin{tabular}{|c|c|c|c|c|}
\hline Variables & Minimum & Maximum & Mean & SD \\
\hline \multicolumn{5}{|c|}{ Continuous (summarised by mean/ward) } \\
\hline Total call rates & 0.029 & 0.337 & 0.144 & 0.051 \\
\hline Information call rates & 0.015 & 0.147 & 0.051 & 0.024 \\
\hline Deprivation (from WIMD) & 1.13 (least) & 74.9 (most) & 22.2 & 14.2 \\
\hline Population density (people/hectares) & 0.043 & 100 & 9.70 & 13.2 \\
\hline Age of residents (years) & 28.8 & 52.2 & 40.4 & 3.3 \\
\hline \multicolumn{5}{|c|}{ Binary (summarised by proportion/ward) } \\
\hline Self callers & 0.357 & 0.900 & 0.609 & 0.107 \\
\hline Digestive symptoms & 0.109 & 0.663 & 0.315 & 0.105 \\
\hline Calls on a Monday & 0.065 & 0.289 & 0.159 & 0.033 \\
\hline Calls on a Tuesday & 0.056 & 0.237 & 0.144 & 0.028 \\
\hline Calls on a Wednesday & 0.060 & 0.267 & 0.141 & 0.027 \\
\hline Calls on a Thursday & 0.034 & 0.243 & 0.137 & 0.024 \\
\hline Calls on a Friday & 0.053 & 0.245 & 0.133 & 0.026 \\
\hline Calls on a Saturday & 0.036 & 0.280 & 0.139 & 0.041 \\
\hline
\end{tabular}

ED, emergency department; WIMD, Welsh Index of Multiple Deprivation.

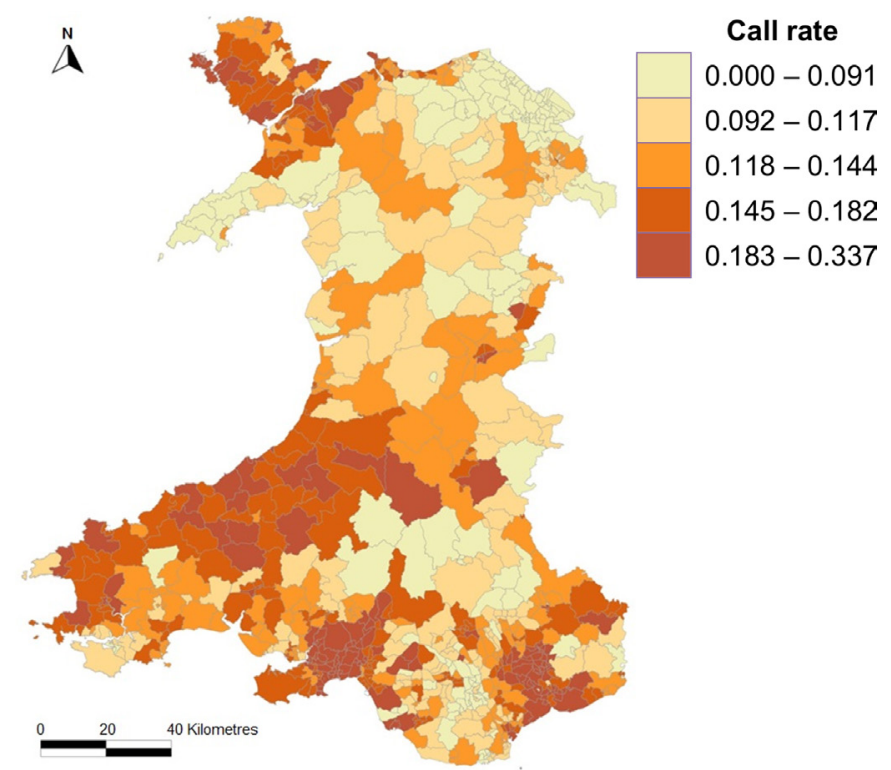

Figure 3 Variation in call rates across Welsh wards. 'Welsh boundaries were derived from Edina Digimap (https:// digimap.edina.ac.uk), an online map and data delivery service run by the University of Edinburgh. Estimated call rates were transposed onto the Welsh map using ArcGIS (www.arcgis. com), a geographical information system for maps and spatial data'. words these variables explain $31 \%$ of variability in advice call rates, but only $14 \%$ of variability in information or all call rates. Adding the proportions of calls on each day of the week ('Block 2') explained a further $2.2 \%$ of variability in advice call rates, $13.3 \%$ of variability in information call rates and $1.0 \%$ of that in combined call rates.

As table 2 shows higher call rates among the most and least deprived groups, we added deprivation ('block 3' models) using two the approaches-first, as linear and quadratic terms; second, as five ordered groups. The first approach proved more effective; tables 5-7 (summarising this approach) show that the adjusted $R^{2}$ improved marginally by $0.001-0.330$ for advice call rates, by $0.008-$ 0.282 for information call rates and by $0.002-0.156$ for combined call rates, compared with counterparts for 'block 2' models. Thus, our final models explained 33\% of the variability in advice call rates, $28.2 \%$ in information call rates and only $15.6 \%$ in combined call rates. The second, less effective, approach of using deprivation in fifths showed smaller marginal improvements in the adjusted $\mathrm{R}^{2}$ for the three variables.

Generally, there was little change in the direction and size of the standardised coefficients in models for the three call rates. Deprivation (when included as linear and quadratic terms, as above) only significantly improved prediction for information call rates; however, the 
Table 4 Pearson correlation coefficients between deprivation and ward-level proportion of calls by day of week for advice, information and total calls

\begin{tabular}{|c|c|c|c|c|c|c|c|c|}
\hline & WIMD & Sunday calls & Monday calls & $\begin{array}{l}\text { Tuesday } \\
\text { calls }\end{array}$ & $\begin{array}{l}\text { Wednesday } \\
\text { calls }\end{array}$ & $\begin{array}{l}\text { Thursday } \\
\text { calls }\end{array}$ & Friday calls & $\begin{array}{l}\text { Saturday } \\
\text { calls }\end{array}$ \\
\hline \multicolumn{9}{|c|}{ Correlations between deprivation (WIMD) and proportion of advice calls by day of week } \\
\hline$P$ value & & 0.171 & 0.019 & 0.030 & 0.118 & 0.000 & 0.003 & 0.02 \\
\hline \multicolumn{9}{|c|}{ Correlations between deprivation (WIMD) and proportion of information calls by day of week } \\
\hline$P$ value & & 0.000 & 0.000 & 0.339 & 0.004 & 0.634 & 0.236 & 0.000 \\
\hline \multicolumn{9}{|c|}{ Correlations between deprivation (WIMD) and proportion of total calls by day of week } \\
\hline WIMD & 1 & 0.154 & -0.166 & -0.117 & -0.127 & 0.078 & -0.130 & 0.162 \\
\hline$P$ value & & 0.000 & 0.000 & 0.001 & 0.000 & 0.026 & 0.000 & 0.000 \\
\hline
\end{tabular}

WIMD, Welsh Index of Multiple Deprivation.

direction of the standardised coefficient differed whether using WIMD as a linear or a quadratic term (table 6). The proportion of the ward population categorised as 'white' was a significant negative predictor of all three call rates with standardised coefficient of $-0.137 \quad(p<0.001)$ for advice calls, $-0.113(\mathrm{p}=0.001)$ for information calls and $-0.184(\mathrm{p}<0.001)$ for combined calls; the more people with a 'white' ethnicity in a ward, the fewer calls. The proportion of callers who called NHSDW for themselves was a strong negative predictor of call rates both for advice (standardised coefficient $=-0.252, \mathrm{p}<0.001$ ) and combined (standardised coefficient $=-0.267, \mathrm{p}=0.001$ ): the more who called for themselves in a ward, the fewer calls. The coefficient for distance to ED was also negative for both advice and all call rates; as distance to the nearest ED increased, the call rates decreased. However, neither self-call rates nor distance significantly predicted information call rates.

\section{DISCUSSION}

\section{Main findings}

Call rates to NHSDW, deprivation scores, distance to hospital EDs and population density all varied greatly across wards in this small but heterogeneous country. Included in our linear regression models, these variables explained much of the variability in call rates across the wards. The low correlation $(r=0.097)$ between advice call rates and information call rates justified the need to look at these separately. However, deprivation only contributed significantly to explaining variation in information call rates, yielding inconsistent evidence of an intrinsic relationship between call rates and deprivation. While the proportion of 'white' residents in a ward predicted all call rates, patterns of use also varied by the proportions of those who called for themselves and day of the week.

\section{Strengths and limitations of this study}

This is the first large national study in Wales exploring demand for telephone-based healthcare-with data on over 400000 calls over 30 months. To understand the influence of deprivation on demand, we included 14 potential independent variables, informed by the existing literature on deprivation and healthcare. We sought transparency in recoding variables using recognised systems $^{28-30} 3233$ and used accepted methods to overcome lack of individual distances to ED. ${ }^{32} 33$ We explored advice calls and information calls both separately and together, and rigorously tested the relationships between deprivation and demand in sequence. Throughout these detailed explorations findings remained consistent: in this population there is no consistent evidence that deprivation affects demand. However, our study has limitations as well as strengths. In particular our data are 15 years old. Also we could not trace callers through the dataset, or distinguish between many unique calls or the same caller phoning several times. Although this study used the recognised ICPC-2 system to code patients' symptoms, this does not measure severity of complaint. Hence, we cannot tell whether those calling from deprived areas had worse health and how this affected demand. Another limitation is the 'ecological fallacy' - the danger of inferring individual trends from the grouped data. ${ }^{34}$ Finally, we could not include those 60000 calls (12\%) without a deprivation score; they could be genuine emergencies where it was not possible to collect all information or uncooperative callers who refused to give their address.

\section{Findings in context}

Other studies have found that call rates to NHSD rose with increasing deprivation but tailed off in the most deprived areas. Our findings show little evidence of any consistent relationship between call rates and deprivation, we judge because of the inclusion of previously overlooked confounding variables like population density, distance to ED and day of the week, which may minimise the intrinsic role of deprivation. Even when deprivation was found to be a significant predictor of information call rates, the direction of the relationship varied whether 


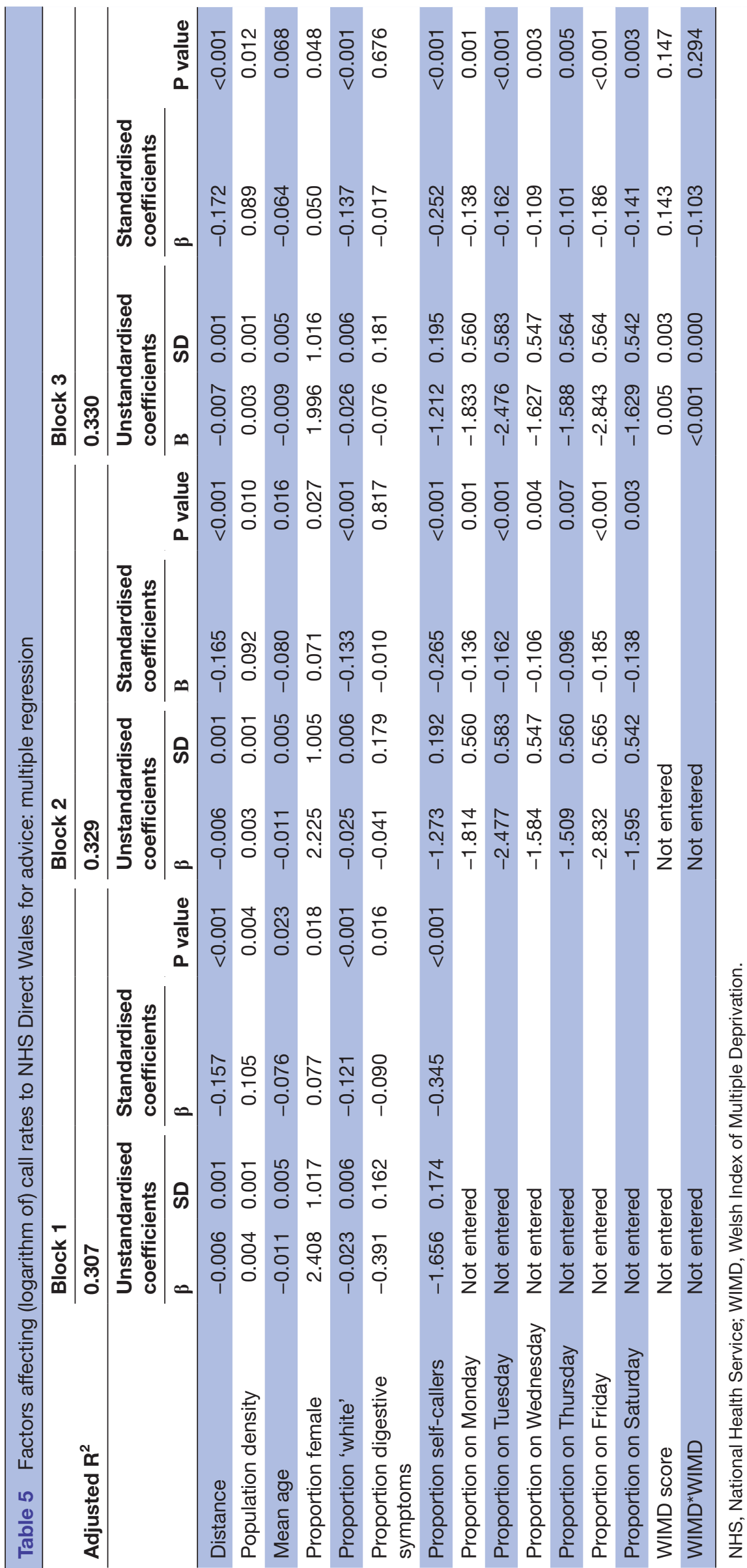




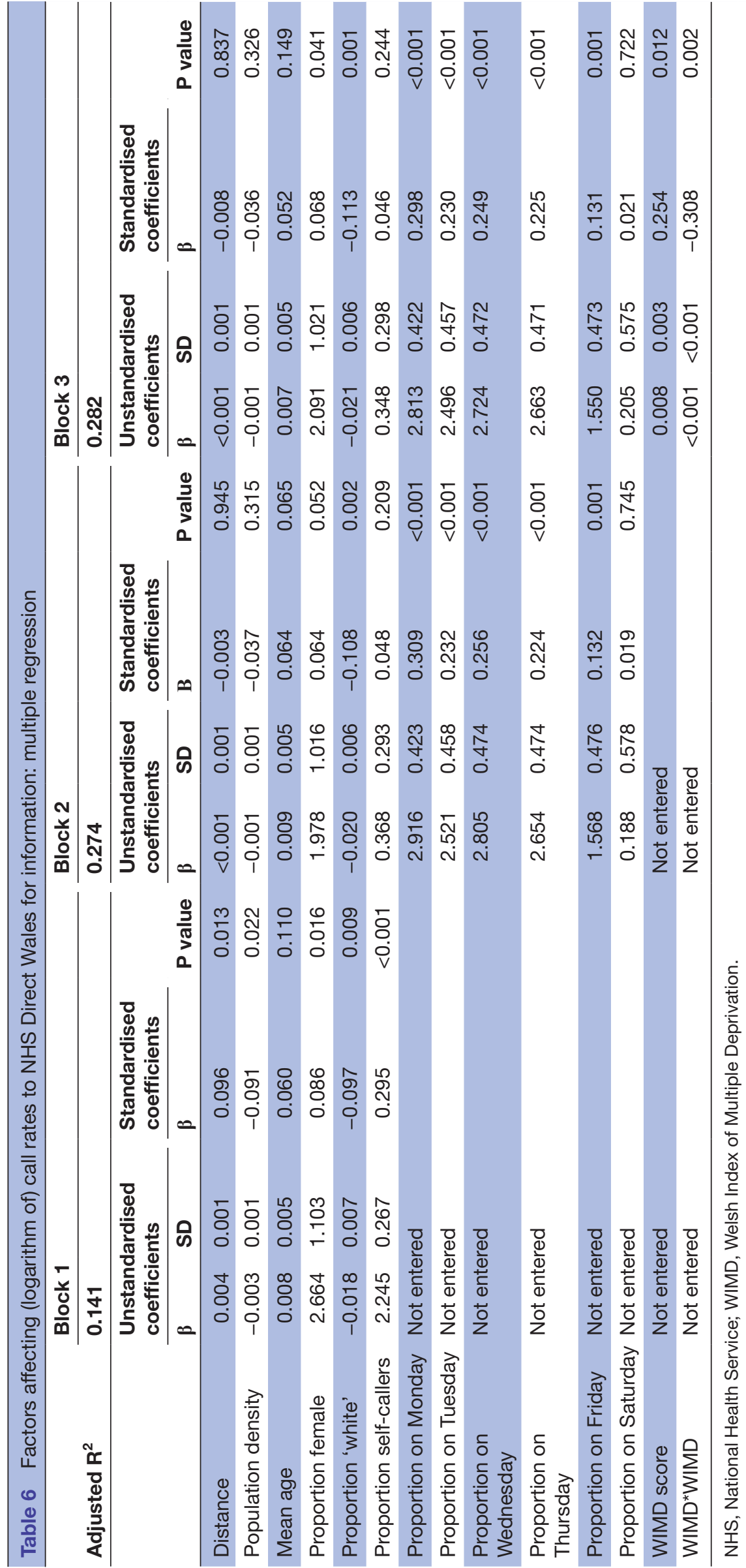




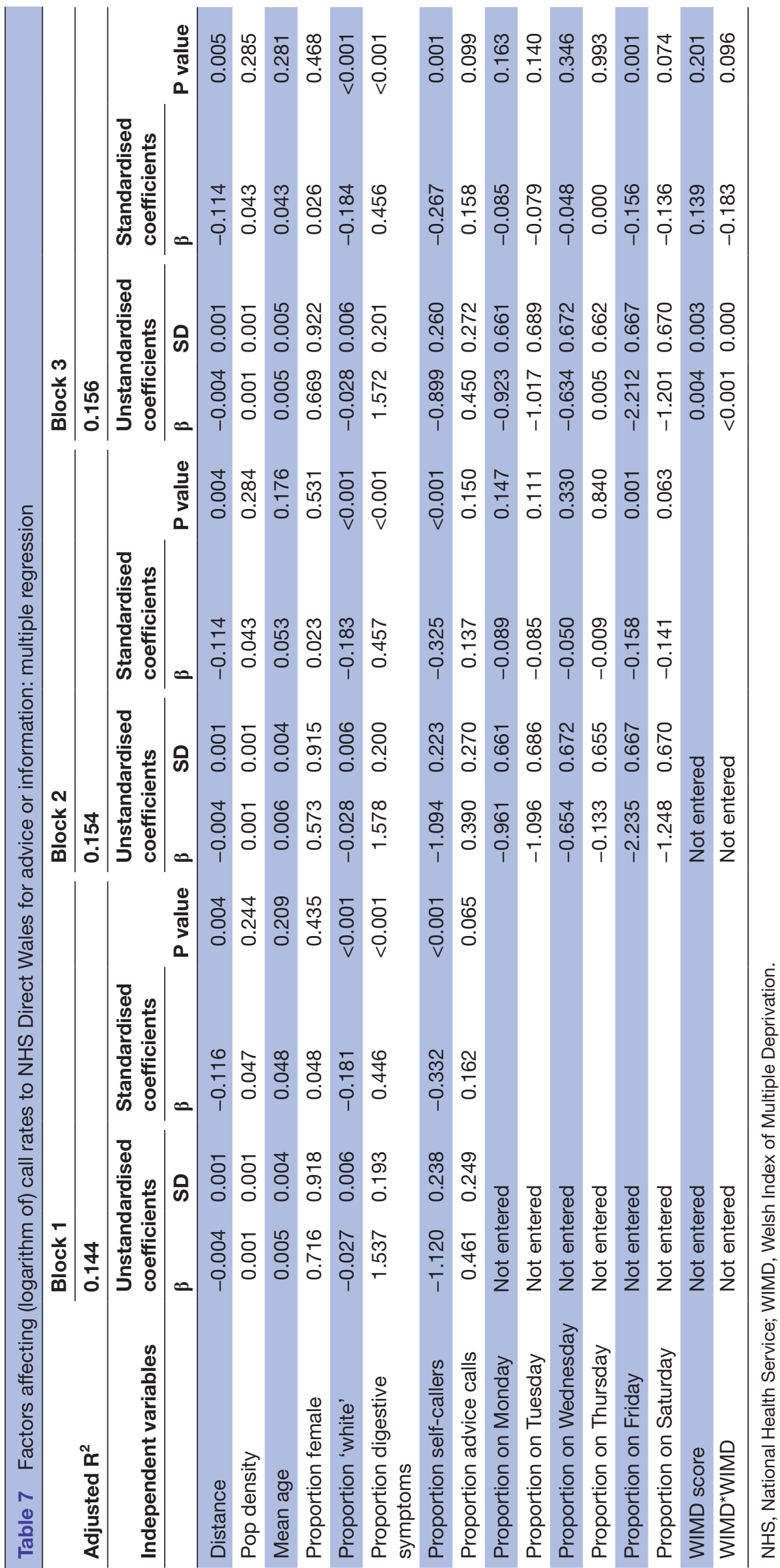


deprivation was included as a linear or quadratic term. Indeed, our findings suggest that demand for NHSD is not as simple as presented in many previous studies conducted at ward level. ${ }^{15-19}$ For example, no study had distinguished between deprivation and advice and information calls separately-types of calls that we have shown behave differently with deprivation. However, our study can identify only socioeconomic influences that operate at ward level and could obscure evidence that suggests that NHSD is being used by those who are better off. ${ }^{1-13}$

\section{Implications}

While we recognise that data presented here are 15 years old, telephone access to service remains a key component of the urgent care system. This study suggests that NHSDW could be one of the least discriminatory health services, and that several of the nine similar previous studies (five of which analysed data at least as old as ours) have overestimated the effect of deprivation on demand. However, the role of patient symptoms in predicting demand needs further exploration, particularly severity of complaint. In future, fortunately, the Secure Anonymised Information Linkage (SAIL) databank ${ }^{35}$ will overcome the other two major limitations of the present dataset-inability to identify repeat callers to NHSD, and lack of data on individual patient circumstances, especially socioeconomic. By combining datasets through anonymous linkage, SAIL can trace patients who contact any service during the period studied, yielding a more accurate picture of service use. We, therefore, recommend anonymous data linkage as an important early step in pursuing these issues.

That said, our finding that there is little evidence in our large national dataset that deprivation affects demand is reassuring. Nevertheless, the expanding breadth and depth of data in SAIL will increasingly enable NHS Wales to monitor whether NHSDW favours any subgroup of society, notably the affluent. Similarly, the NHS in the rest of the UK has increasing capacity to monitor inadvertent discrimination in service delivery. Finally, the finding that calls varied by day of week has implications for staffing of telephone-based healthcare services

\section{CONCLUSIONS}

This study has identified previously unexplored differences in the rates of calls to NHSD for advice and for information. We have characterised many factors that influence demand for NHSD. Nevertheless, much variation in call rates remains unexplained. In particular, individual socioeconomic indicators that we did not have may yet help to predict call rates. While our data may have underestimated the 'need' of deprived patients for healthcare, they yield no evidence that policy-makers should seek to improve access to NHSD for those patients. Although these patients may go elsewhere for healthcare, we have shown that NHSD Wales provides equitable access in response to ward-specific deprivation.
Acknowledgements We are grateful to NHSDW for providing the data for this study. We thank Greg Fegan for his helpful contribution to the subsequent analysis of these data.

Contributors JP and HS designed the study. JP cleaned, managed and analysed the data, and drafted and revised the paper. JP is guarantor. SM provided expertise in informatics, SR provided expertise in medical geography, ITR and AW provided expertise in statistics, and HS provided expertise in emergency care. All authors revised the draft paper.

Funding The authors have not declared a specific grant for this research from any funding agency in the public, commercial or not-for-profit sectors.

Competing interests None declared.

Patient consent for publication Not required.

Ethics approval We received ethical approval from the South East Wales Local Ethics Committee in September 2004.

Provenance and peer review Not commissioned; externally peer reviewed.

Data availability statement Data are available on reasonable request.

Open access This is an open access article distributed in accordance with the Creative Commons Attribution Non Commercial (CC BY-NC 4.0) license, which permits others to distribute, remix, adapt, build upon this work non-commercially, and license their derivative works on different terms, provided the original work is properly cited, appropriate credit is given, any changes made indicated, and the use is non-commercial. See: http://creativecommons.org/licenses/by-nc/4.0/.

\section{ORCID iDs}

Julie Peconi http://orcid.org/0000-0003-1221-827X

Sarah E Rodgers 0000-0002-4483-0845

Alan Watkins http://orcid.org/0000-0003-3804-1943

\section{REFERENCES}

1 Victora CG, Vaughan JP, Barros FC, et al. Explaining trends in inequities: evidence from Brazilian child health studies. Lancet 2000;356:1093-8.

2 National Public Health Service for Wales. Deprivation and health. NPHSW: Cardiff, 2004.

3 World Health Organisation. Global Commission on social determinants of health 2008. Geneva, Switzerland: WHO, 2019. http://www.who.int/social_determinants/thecommission/finalreport/ en/index.html

4 Institute of Health Equity. Fair Society healthy lives: the Marmot review final report. London: University College, 2010. www.institut eofhealthequity.org/projects/fair-society-healthy-lives-the-marmotreview

5 Department of Health, CMD. The new NHS: modern, Dependable. London: The Stationary Office, 1997.

6 Department of Health. Our NHS our future: NHS next stage review interim report. London: DH, 2007. Gateway reference 8857.

7 Welsh Government. Our plan for a primary care service for Wales up to March 2018, 2014.

8 George S. NHS direct audited. BMJ 2002;324:558-9.

9 Scottish Government Team. Report: review of NHS 24. Edinburgh: Scottish Government, 2005. http://www.scotland.gov.uk/ Publications/2005/10/NHS24Report

10 Snooks HA, Williams AM, Griffiths LJ, et al. Real nursing? The development of telenursing. J Adv Nurs 2008;61:631-40.

11 Ring F, Jones M. NHS direct usage in a GP population of children under 5 years: is NHS direct used by people with the greatest health need? Br J Gen Pract 2004;54:211-3.

12 Knowles E, Munro J, O'Cathain A, et al. Equity of access to health care. Evidence from NHS direct in the UK. J Telemed Telecare 2006;12:262-5.

13 Shah SM, Cook DG. Socio-economic determinants of casualty and NHS direct use. J Public Health 2008;30:75-81.

14 Cook EJ, Randhawa G, Large S, et al. Who uses telephone based helplines? Relating deprivation indices to users of NHS direct. Health Policy Technol 2013;2:69-74.

15 Burt J, Hooper R, Jessopp L. The relationship between use of NHS direct and deprivation in Southeast London: an ecological analysis. $J$ Public Health 2003;25:174-6.

16 Cooper D, Arnold E, Smith G, et al. The effect of deprivation, age and sex on NHS direct call rates. Br J Gen Pract 2005;55:287-91.

17 Cook EJ, Randhawa G, Large S, et al. A U.K. case study of who uses NHS direct: investigating the impact of age, gender, and deprivation on the utilization of NHS direct. Telemed J E Health 2012;18:693-8. 
18 Hsu W-C, Bath PA, Large S, et al. The association of geographical location and neighbourhood deprivation with older people's use of NHS direct: a population-based study. Age Ageing 2013;42:57-62.

19 Bibi M, Atwell RW, Fairhurst RJ, et al. Variation in the usage of NHS direct by age, gender and deprivation level. J Environ Health Res 2005;4:63-8.

20 Peconi J, Macey S, Rodgers S, et al. Advice given by NHS direct in Wales: do deprived patients get more urgent decisions? Study of routine data. J Epidemiol Community Health 2017;71:849-56.

21 Dixon-Woods M, Cavers D, Agarwal S, et al. Conducting a critical interpretive synthesis of the literature on access to healthcare by vulnerable groups. BMC Med Res Methodol 2006;6:35

22 Darlington RB. Regression and linear models. Columbus, $\mathrm{OH}$ : McGraw-Hill, 1990.

23 Hosmer DW, Lemeshow SL. Applied logistic regression. 2nd edn. Hoboken, NJ: Wiley, 2000

24 O'Reilly D, Stevenson M, McCay C, et al. General practice out-ofhours service, variations in use and equality in access to a doctor: a cross-sectional study. Br J Gen Pract 2001;51:625-9.

25 Turnbull J, Martin D, Lattimer V, et al. Does distance matter? Geographical variation in GP out-of-hours service use: an observational study. Br J Gen Pract 2008;58:471-7.

26 Turnbull J, Pope C, Martin D, et al. Do telephones overcome geographical barriers to general practice out-of-hours services? Mixed-methods study of parents with young children. J Health Serv Res Policy 2010;15:21-7.
27 Peconi J. The epidemiology of demand for, and outcomes of contacts with, telephone based healthcare with particular reference to ward deprivation scores: analysis of calls to NHS Direct Wales 2002-2004 [PhD thesis]. Swansea University: College of Medicine, 2014: 497.

28 World Health Organisation. International classification of primary care (ICPC-2). 2nd edn. Geneva, Switzerland: WHO, 2003. http://www. who.int/classifications/icd/adaptations/icpc2/en

29 Department of Health. A Practical guide to ethnic monitoring in the NHS and Social Care. 2005

30 Welsh Index of Multiple Deprivation. Local authority profiles. Cardiff: Welsh Office, 2000. http://wales.gov.uk/statistics-and-research/ welsh-index-multiple-deprivation/?lang=en

31 Hanigan I, Hall G, Dear KBG. A comparison of methods for calculating population exposure estimates of daily weather for health research. Int J Health Geogr 2006;5:38.

32 Judge A, Welton NJ, Sandhu J, et al. Equity in access to total joint replacement of the hip and knee in England: cross sectional study. BMJ 2010;341:c4092.

33 Geoconvert: UK data service census support. Available: www. geoconvert.mimas.ac.uk [Accessed 6 Dec 2013].

34 Morgenstern $\mathrm{H}$. Uses of ecologic analysis in epidemiologic research. Am J Public Health 1982;72:1336-44.

35 Lyons RA, Jones KH, John G, et al. The SAIL databank: linking multiple health and social care datasets. BMC Med Inform Decis Mak 2009;9. 